Article

\title{
Principles and Policies for Recycling Decisions and Risk Management
}

\author{
Jonatan Gehandler *(i) and Ulrika Millgård \\ RISE Research Institutes of Sweden, Box 857, 50115 Borås, Sweden; ulrika.millgard@ri.se \\ * Correspondence: jonatan.gehandler@ri.se; Tel.: +46-105-165-090
}

Received: 19 August 2020; Accepted: 8 September 2020; Published: 10 September 2020

check for updates

\begin{abstract}
Swedish recycling businesses argue that the Non-Toxic Environmental target gets too much weight and that resource efficiency gets too little focus, which results in decreased recycling. The purpose of this paper is to highlight different factors that recycling of waste decisions should consider, as well as contributing to a constructive discussion of the overall principles and policies for recycling. How recycling works in practice is explored based on nine interviews with stakeholders from the governmental agency level to recycling businesses. Theory with regards to ethics, risk, decision-making, governmental policy and laws is summarised. Finally, the discrepancy and connection between practice and theory is analysed. If recycling of waste is seen as a decision problem, the choice is between to recycle (in different ways) or not to recycle (i.e., energy recovery and/or landfill). Based on risk and decision theory, all relevant goals should be considered. This requires a broader problem framing when goals are in conflict. All parties agree that recycled and virgin material should be treated equally. From a higher policy perspective, it should then be demonstrated that any use of material (recycled and/or virgin) minimize environmental impact and promotes long-term sustainability.
\end{abstract}

Keywords: recycling; circular economy; decision-making; risk management; conflicting goals; ethics

\section{Introduction}

Political goals and visions indicate the long-term desired development. In addition to the goal of a limited climate impact and long-term sustainability, two of the sixteen Swedish environmental goals affect recycling of waste: the goal of a Non-Toxic Environment and resource efficiency under the goal of a Good Built Environment.

If political goals specify the long-term desired development, laws specify how the policy should be interpreted here and now. The waste sector is carefully regulated by laws, limit values, penalties and public monopoly. Guidelines are developed so that authorities can make many and consistent decisions. The Swedish Environmental Protection Agency has published a guideline [1] that applies to recycling within construction work. In 2015, the guideline was evaluated through a survey [2]. The result showed that the guideline had not increased recycling in construction work. On the contrary, $64 \%$ of those who evaluated the guideline consider that recycling has decreased. One view expressed during the evaluation is that levels of acceptable environmental risk are too low. It is also argued that the Non-Toxic Environmental target gets too much weight and that resource efficiency gets too little focus. As the climate issue becomes more acute, and since recycling in many cases reduces the climate impact, this limitation can be called into question. However, it is unclear how a better balance between a non-toxic environment and resource efficiency could be struck.

How recycling should work can be seen as a political decision problem. In 1793, the French philosopher and mathematician Condorcet prepared a carefully developed proposal for the Constitution of France. In the proposal, a democratic decision-making process was laid out in three steps. In the 
first step the basic principles of the decision are discussed. In this step, perceptions are personal, and no attempt is made to form a majority. In the second step, the question is clarified, and opinions are approached and combined with each other to create a limited number of alternatives. In the third step, the decision is made by vote [3]. This paper aims at Condorcet's Step 1; to clarify the basic factors and principles for recycling decisions.

\section{Paper Outline}

This paper consists of three main Sections. The Theory Section reviews fundamental factors that impact recycling decisions. Recycling in Sweden is described in the Practice Section. In the Analysis Section, the practice is analysed with regards to the theory and lessons learned are identified. This process and paper outline are visualized in Figure 1.

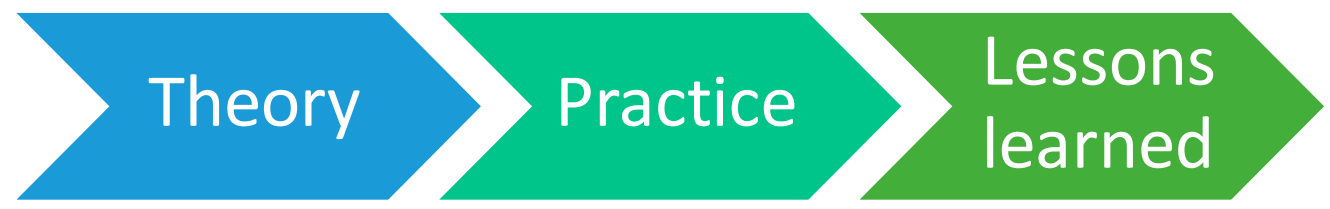

Figure 1. The paper starts with theory in Sections 3 and 4, describes recycling in practice in Section 5 and lessons learned are identified in Section 6.

The theory is found in Sections 3 and 4, divided into two parts. The purpose of the theory is to use the literature to describe the main features of the overall factors that influence the choice of a decision or risk assessment method for recycling. Theory-part one in Section 3 provides theory about risk decisions and basic steps that should be included in a decision-making process, from problem framing to evaluation. We will see that the choice of problem framing is a complex, political, and very important step. The second theory-part in Section 4, ethics, presents theory of ethical aspects linked to decisions. Ethics is central, because it has long sought answers to the question of how we should act. We will learn that there are two main ethical thought patterns to justify decisions; a utility-based or limit-based approach.

How recycling in Sweden works today in practice is the focus of Section 5. The section reviews existing political goals, laws and guidelines, and provides examples of difficulties that may arise in the practical application. Interviews and a workshop were conducted with selected stakeholders, from the governmental agency level to recyclers. The intention has not been to describe how recycling works in detail. Rather, the intention has been to describe how recycling works on a more general level; what goals govern? How are decisions justified? What works well and what works less well?

The analysis is presented in Section 6. Taking a philosophical approach, this section has a debating character. In this section, theory is applied to practice. Recycling in practice is discussed in relation to the theory. Several recommendations, or lessons learned, are identified.

\section{Method}

The method consisted of a literature study, interviews and a thematic workshop. Finally, the link between theory and practice was analysed. One approach throughout this work was that any opinion or principle that concerns the problem was regarded as being worthy of being expressed, no matter how many or few were behind it, or whether it was new or well-established; the important thing was that the problem description became nuanced. Interviews were conducted with the aim of understanding the situation and capturing the different perspectives of business operators and authorities, without valuing how many or few people were behind different opinions. Ten interviews were conducted with representatives from the following organizations.

- Kemikalieinspektionen (Swedish Chemical Agency)

- IKEM-The Innovation and Chemical Industries in Sweden 
- Naturvårdsverket (Swedish Environmental Protection Agency)

- Waste Sweden (industry organization for waste incineration)

- Stena Metal (recycling business)

- Sysav Utveckling AB (waste incinerator)

- County Administrative Board VG

- Stockholm City, the chemical centre

- Borås City (Local municipality)

- The Department of Philosophy (Environmental Ethics), Lund University

In these interviews, open exploratory questions were used, such as "What values or goals guide your work on recycling of waste?", "How do you work towards the Non-Toxic Environmental target?" or "Can you describe how different values can conflict?", with the opportunity to adapt or pose new questions during the conversation. In this sense, all interviews were semi-structured [4].

From the interview study, the theme "The Non-Toxic Environmental target and the difficulties that can arise in its practical application" crystallized. This theme was discussed further in a workshop. Invited to the workshop were mainly those who had been interviewed and had vital roles for the chosen theme.

\section{Theory, Part One: Decision-Making and Risk Management}

There is no guarantee that a certain decision will produce the desired outcome. In a certain case, a well-founded decision can lead to undesirable consequences and a poorly informed decision can lead to favourable consequences. However, in the long run, we imagine that a large number of well-founded decisions lead to better outcomes than poorly substantiated ones. What is important in decision and risk management is not what is decided but how decisions are made. According to Hammond et al. [5], an effective decision-making process meets the following criteria:

1. It focuses on the most important.

2. It is logical and consistent.

3. It considers both subjective and objective factors and mixes analytical and intuitive thinking.

4. It requires only as much information and analysis that is necessary to solve a specific dilemma.

5. It encourages and guides the collection of relevant information.

6. It is straightforward, reliable, easy to use and flexible.

Central to all risks is that they have a fact dimension and a value dimension. Based on existing facts and knowledge, a more or less uncertain prediction can be made of an expected outcome. No risk is free from values, which are connected to the facts dimension and the type of uncertainty that is emphasized. The challenge for risk management decisions is often about separating facts from values to a sufficient extent to enable an informed and well-structured decision-making process [6].

For a general decision-making process, the following equally important steps can be identified.

1. Problem framing.

2. Specification of objectives.

3. Alternatives and possible solutions.

4. Facts analysis of how well the goals are being achieved (facts).

5. Evaluation of the best solution (value).

6. Choice of solution or iteration.

\subsection{Problem Framing}

According to Lundgren [7], the choice of problem framing is to a large extent a political issue and forms part of the ongoing conflict of interest and the struggle for power in society. Those who have 
influence over the problem framing also have power over the continued development of the problem. In democratic societies, the problem framing should be negotiated by representative stakeholders.

How a problem is described and framed is important because it greatly affects which factors are being considered. For example, a technical problem description indicates that it is about engineering the best solution, a socio-technical problem description includes the society and the context in which the technology is used, and an ethical perspective can include justice, empathy and emotions.

\subsubsection{A System Perspective: A Soft and/or Hard Problem?}

Recently the scientific method has been complemented with a system perspective. Checkland [8] makes a distinction between hard and soft system theory. Hard system theory works well with a relatively clear problem and goal description. The task of the systems engineer is to design the system so that the goals are met. An example could be technical infrastructure or an academically delimited problem. Soft system theory is developed for problems that are difficult to define or where multiple goals conflict. It can be about exploring vague situations that are perceived as problematic. An example of a soft problem is how a human welfare can be provided with limited resources. A soft system perspective can help to better understand the situation and act in a meaningful way beyond limited or short-term goals. Hard systems theory is often based on a technical worldview taken for granted. In soft systems theory, the worldview itself is questioned, though not completely relativized. The worldview may change, for example from a technical worldview to a political worldview, if it can better describe the problem, reach solutions, and create meaning.

Several recent changes are challenging our worldview. With the industrial revolution and the information revolution, more and more problems must be seen as global rather than local. As Checkland [8] puts it, the world is increasingly becoming a global village where we should see ourselves as the crew of spacecraft Earth). At the same time, Checkland argues that the worldview is deeply rooted in man and that it is difficult to change it.

\subsubsection{Post-Normal Science}

Funtowicz and Ravetz [9] argue that decisions under major uncertainties and where large values are at stake, often have a too narrow problem framing (and consequent solution) by current stakeholders. Instead, they argue that such problems are best solved by what they call post-normal science, which is a more democratic form of problem-solving where everyone is legitimate to contribute to the solution of the problem. They believe that this is necessary to be able to resolve several conflicts today regarding technological risks and its far-reaching consequences for people and the environment. Similar to how many people today can read, write, vote and engage politically, people should also be able to contribute to problem-solving of technological risks that are currently reserved for a certain type of education, method or profession [9].

\subsubsection{Complexity, Uncertainty and Ambiguity}

Klinke and Renn [10] identify three challenges for risk management: complexity, uncertainty and ambiguity. Complexity refers to difficulties in identifying causal links between cause and effect, for example due to a long-time delay between cause and effect. By uncertainty is meant that a stronger prediction cannot be done due to statistical variation or knowledge limitations. Ambiguity is about that different stakeholders can make different legitimate interpretations from the same data or evidence. Please note that it is wrong to believe that ambiguity should always be minimized. Reduced ambiguity risks concealing conflicts or simplifying complex relationships so that they are inconsistent with reality. An increased level of ambiguity in a positive sense occurs when ignorance, deviations and details are made visible [11].

\subsection{Specification of Objectives (and Risks)}

There are many definitions of risk, but the choice of definition often involves a valuation and can therefore be controversial. Risks are about threats to desirable outcomes, which are valued positively. 
Defining something as a risk is an exercise in focusing thinking on what we value. Then these desirable outcomes are specified clearly enough for us to choose between them. For some outcomes, there are generally accepted yardsticks, such as annual numbers of deaths. This, like many other outcomes, contains two dimensions. Firstly, the measurable number and the evaluation of how bad (undesirable) it is, e.g., with $X$ number of deaths. This means that even when we have access to something measurable, such as the number of deaths, we still do not escape the valuing dimension. For other outcomes, the very idea of a yardstick can be controversial. Within engineering, risk is usually seen as a combination of consequence and probability, which can then be expressed as expected consequence, a measure that economists often use in cost-benefit analysis (CBA). The risk measure should be related to the decision situation in question. If, as an individual, you must choose between different modes of transport for a journey, one should consider the entire movement from start to finish, throughout the journey [12]. For example, during a flight trip you need to include the transport to and from the airport. More complex risks can be captured by several indicators, such as healthy ecosystems that could be represented by the health of key species.

\subsection{Alternatives and Possible Solutions}

Since no decision is better than the best option, it is understood that this also is an important decision step. According to Hammond et al. [5], a so-called status quo option, or reference option, should be defined as a sound frame of reference to evaluate other options against. Normally, the status quo option is initially "do nothing". Once a better solution has been identified, this solution can represent the status quo in the search for even better options.

\subsection{Facts Analysis}

The analysis is strongly linked to the goals that are set, these are the ones that need to be analysed and rated. The analysis also depends on the options that are generated. To then be able to evaluate the alternatives and identify the best alternative based on available facts, it is primarily important to analyse the differences that exist between the different options, for example between different ways of recycling and the alternative not to recycle. Methods can be, for example, an environmental risk assessment (ERA) that evaluates the Non-Toxic Environmental target, a life-cycle analysis that evaluates resource efficiency, or an ethical analysis that evaluates ethical aspects such as who benefits and who is exposed to risks.

\subsection{Evaluation}

According to the Scottish philosopher David Hume (1711-1776) we cannot deduce an 'ought' from an 'is' (Hume, 1738). Most philosophers agree that we cannot derive value statements (the 'ought') from factual statements (the 'is'). We cannot therefore deduce, based on facts alone, how we should decide, for example whether we should recycle or not. A valuation is necessary. This should not be interpreted as that facts are unimportant, on the contrary, facts can guide our values and how we should act [13]. Within decision theory, expected utility is the main paradigm for identifying the best solution [14]. Expected utility is a common concept within CBA and economics, the science of managing scarce resources.

Another way to include stakeholders' values is through multi-criteria analysis (MCA), which is used within the environmental field in Norway and the Netherlands [15]. Multi-criteria methods can also include parameters that cannot be expressed in risk measures or monetary units, such as fairness [16]. The aim is to identify the overall best alternative given all the specified objectives.

Setting a "price" on the environment or comparing the different scales local-regional-global, or present-future is not easy. According to a study by Naturvårdsverket [15], it is considered difficult to make cost estimates of environmental benefits in the area of contaminated land in Sweden. However, it is also argued that the process, although perceived as difficult, drives the decision forward through 
the discussions regarding how different objectives should be valued. Often, this comparison is made by a ranking of pros and cons for the different alternatives.

\subsection{Linked Decisions and a Long-Term Perspective}

What is decided today can affect what can be decided tomorrow. The long-term goals should influence the choices we make today. Many decisions are what Hammond et al. [5] call linked decisions. According to Hammond et al. it is important to make decisions on an ongoing basis here and now while collecting information to resolve future decisions. To make smart decisions now, we need to think about what type of decisions we want to make in the future. Another important aspect of linked decisions is to constantly learn from the decisions that are being made.

The Non-Toxic Environmental goal has been criticized for being utopian (based on a literal interpretation) and unrealistic (based on an interpretation that health and biodiversity are not threatened by substances and metals created or extracted by society), given what reality looks like [7].

Another visionary goal, Vision Zero within road traffic $[17,18]$ has had a major impact worldwide since its launch in the 1990s and is seen by some as an innovation in the safety field [19,20].

Criticism against the Vision Zero argue that the vision, through the large support and political acceptance, removes a healthy societal debate, that it gives a false picture of absolute safety, or that the vision from an economic perspective, if you really try to reach it (zero dead, a reduction of a few hundred), requires large amounts of resources that must be taken from other important social functions. This, according to Elvik [21], leads to far more deaths (thousands) overall in society, for example resulting from that resources due to increased investments in the traffic area are taken from health care.

\section{Theory, Part Two: Ethics}

From a legal perspective, there are legal principles of equal treatment. Decisions made by authorities should therefore be consistent. However, what should be consistent is not obvious. It is often considered that the standard risk management model, which is based on facts in terms of the size of the risk in terms of probability and consequence, creates the conditions for consistent decisions. However, as Hermansson [22] points out, it is equally logical to require consistent decision-making from an ethical perspective. An ethical consistency could focus on a fair distribution of benefits and risks and a fair decision-making process that includes those affected by the risk.

Since ethical factors are of crucial importance for risk decisions, Ersdal and Aven [23] advocate decision-making methods that highlight and discuss ethical dilemmas, such as MCA. They warn against methods that hide ethical issues, such as limit-based risk criteria, or CBA.

\subsection{Normative Ethics}

As previously pointed out, according to Hume's law, we cannot deduce, merely based on facts, how we should act. A valuation is necessary. Normative ethics is central in this regard since it deals with how we should act (i.e., what makes a decision right) [24]. Within normative ethics, there are two dominant ethical thought patterns about how we should act; deontological and consequentialist theory. According to deontology, an act has an intrinsic value that is determined by whether the act has been performed in accordance with a current ethical norm, such as a duty, right or a safety level [25]. This contrasts with Consequentialism, which assesses the action according to its consequences. According to consequentialism, one should choose the course of action that has the best overall consequences. The most common consequentialist theory is utilitarianism, which means that it is the total outcome ("from the viewpoint of the universe") that should be counted. The right action is then the one that maximizes the benefit, that is, maximizes the outcome of happiness and minimizes the outcome of suffering [26]. 


\subsubsection{Utilitarian Ethics}

Most decision-making rationale is based on maximizing the utility. From a risk perspective, it can be seen as an economic innovation to express risk in terms of negative utility, which allows the risk to be compared to other utilities [27]. For example, by putting an instrumental value on a person's life, the risk can be expressed in economic terms. The utility-based perspective allows safety to be relative to other benefits.

Objections to a utility-based approach are that it disregards distribution issues, which is important in deontological ethics. For example, exposing one or more persons to risk becomes justifiable if it is outweighed by the benefits to another person, which can obviously be ethically and democratically questionable. Another objection is that future costs are given much smaller weight through the economic practice of discounting. Furthermore, the more serious consequences of, for example, climate change do not occur within the time period that normal economic calculations usually consider [28].

Although strong objections can be made to strict application of the dominant CBA method (see, e.g., [6]), the basic idea of weighing advantages against disadvantages is not lost. On the contrary, this is a central idea for what is often called rational decision-making. However, a prerequisite is that all steps in the decision-making process are sufficiently considered.

\subsubsection{Deontological Ethics}

Much risk management practice is based on that the risk should be below a certain level that is acceptable or tolerable. This approach reflects deontological ethics (duty ethics) that set certain limits (duties) on what we can do. One such duty relevant to the safety area is that one should not harm others. Based on the "first law" of toxicology, all substances can be toxic. Only the dose allows something to be non-toxic. Thus, a limit-based approach seems attractive. An obvious problem with a limit-based perspective is that the choice of risk or limit is arbitrary. For example, what "conservative fraction" of animal toxicity level represents a "safe" human exposure? Another problem is that limits over time tend to become too conservative. From the deontological perspective, safety is something absolute that cannot be explicitly weighed against other objectives. This can lead to that a strict limit-based approach creates greater risks than those risks that are avoided, as was shown in the Vision Zero example earlier $[16,21,29]$.

\subsection{Environmental Ethics}

In Western civilization man is regarded as exalted above nature, free to use it to his advantage. Currently we are affecting the environment to such an extent that human welfare is threatened by serious consequences and ultimately the basis for the continued existence of human civilization is threatened [30].

Within the normative ethics described above, the question "what makes a decision or action right" dominates. In environmental ethics, the question "who or what is an ethical object, i.e., who or what do you need to consider?" dominates. These two can be seen as a matrix. On one axis there are deontological and consequential ethical theories and on the other axis the ethical objects that we consider.

When it comes to the question "who or what to consider?", there is a scale from "just humans" to "all life" (including animals, plants and habitats). The answer most often assumed is that all humans and only humans are moral objects (anthropocentrism). However, that only humans are moral objects has proved to be problematic and many moral philosophers today do not consider it a viable theory. On the other hand, it is practically difficult, not to say impossible, to take everything into account. For example, it is difficult to say that one has moral obligations to carrots or microorganisms. According to the interviewed environmental ethicist, a reasonable compromise is therefore to assume that it is conscious beings that one should consider. 


\subsection{Ethical Analysis}

Risk issues such as: "what action should be taken given the uncertainty and evidence that a certain substance is toxic?" tend to be addressed as factual problems: "is the substance toxic?" According to Hansson [31], an ethical analysis can help to resolve risk issues through identifying the underlying values that create the conflict. The idea of an ethical analysis is to contribute to a multidimensional view of risk, which also advocates active participation by the concerned public. An ethical approach contrasts with quantitative risk assessment using pre-established criteria of acceptable or tolerable risk as a decision rule.

Three Important Roles

From an ethical perspective, Hermansson and Hansson [32], further developed by Hansson [31], identify three important parties in an ethical analysis for risk decisions: the risk-exposed, the beneficiary, and the decision maker. There are often several parties that are risk-exposed, such as workers, neighbours, residents, consumers, future generations and members of other species. In the same way, there may be more beneficiaries and decision makers. The situation is easiest if the three parties are the same person and more complicated if decision makers and beneficiaries gain from putting others at risk.

Which risks that are accepted is a negotiation between the three roles above. Can the risk be reduced? Can vulnerable people be compensated? This is often a controversial issue, but what is crucial in this context is not to determine a certain acceptable level of risk, but how to merge knowledge, power and ethics. In a democratic society, a sincere debate about these issues is crucial [33].

To summarize, the factors in Figure 2 are identified from theory and ought to be considered for recycling decisions.

\begin{tabular}{|c|c|}
\hline \multirow{6}{*}{ 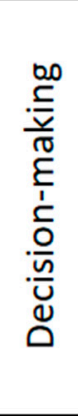 } & $\begin{array}{l}\text { Problem framing (soft/hard problems, complexity, uncertainty and } \\
\text { ambiguity \& post-normal science) }\end{array}$ \\
\hline & Specification of objectives (and risks) \\
\hline & Alternatives and possible solutions \\
\hline & Analysis (facts) \\
\hline & Evaluation (value) \\
\hline & Linked decisions and a long-term perspective \\
\hline \multirow{2}{*}{ 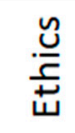 } & Justification by a limit-based and/or utility-based approach \\
\hline & Ethical analysis of risk-exposed, beneficiary and decision-maker \\
\hline
\end{tabular}

Figure 2. Identified factors from theory that impact recycling decisions.

\section{Theory and Practice of Recycling in Sweden Today}

This section aims to describe how recycling of waste overall works in Sweden today, partly based on literature, goals, laws and guidelines (theory) and partly based on interviews and the workshop (practice).

\subsection{Goals and Visions}

From interviews and the literature, it is clear that the goal of a Non-Toxic Environment is the governing goal for authorities. Authorities consider that loops to a large extent should be detoxified 
now. One view from businesses is that, although this may work in smaller loops within Europe, it is in practice difficult to obtain such clean material loops. Several large material loops contain a mixture of products produced at different times and based on different regulations. Even for materials that comply with REACH (1907/2006 Registration, Evaluation, authorization and Restriction of Chemicals), recycling from a non-toxic perspective (in terms of content) can be impossible, for example for products containing flame retardants. Detoxifying loops is ineffective when toxic substances constantly enter the loop.

\subsection{Regulation}

Chapter 2, § 5 in the Swedish Environmental Code (1998:808) states that business activities should manage raw materials and energy cautiously with the ambition to: (1) reduce the amount of waste, (2) reduce the amount of harmful substances in materials and products, (3) reduce the negative effects of waste, and (4) recycle waste. The Environmental Code states the overall goals and principles for environmental consideration. For example, the code states the following six legal principles: the knowledge requirement, the precautionary principle, the product choice principle, the housekeeping principle, the location principle and the reasonableness balance. According to Chapter 2, Section 7 , a reasonable balance must weigh the environmental benefits of protective measures and other precautionary measures against the costs of such measures.

When waste is recycled and used to produce new products, the product and chemical regulation applies (REACH, CLP; 1272/2008 on the Classification, Labelling and Packaging of substances and mixtures, and POP; 850/2004 on Persistent Organic Chemicals). In this legislation for chemical products, chemical substances recycled from waste are treated in principle the same way as virgin substances. One difference, however, is that already-registered substances do not need to be re-registered when they are recycled. The international POP rules prohibit certain particularly dangerous substances. The recycling of such POP substances is in principle prohibited. There are also specific product rules for certain chemicals such as pesticides or specific commodities such as cars and electronics. Anyone who causes waste to cease to be waste is thus regarded as a manufacturer in accordance with the chemicals legislation and needs to comply with these rules, for example regarding the content of hazardous substances. The manufacturer is responsible for ensuring that the products placed on the market are safe, which includes the entire product life cycle including the waste phase [34].

A process for risk assessment (i.e., Chemical Safety Assessment) within REACH has been developed by ECHA, the European Chemicals Agency. The process is governed by a comprehensive regulatory framework with demands on information and investigations. Central to the risk assessment are the concepts of hazard, exposure and risk. The hazard assessment provides information about the danger of the substance's intrinsic properties. The exposure assessment looks at the environment and people's exposure based on the use of chemicals or products. The risk is then characterized based on both the hazard and exposure assessment.

According to REACH, the manufacturer is obliged to consider the entire life cycle of their products, but it is clear from interviews that this does not mean that products today are recyclable. Furthermore, there are no means for recycling operators to give feedback to producers about the recyclability of their products.

Although all parties agree that the same requirements should apply to virgin materials as well as recycled materials, they are often treated differently in practice. Sometimes recycled material is allowed to contain a higher degree of pollution (e.g., recycled PVC), and sometimes the opposite happens, for example, virgin stone may contain radon, but not recycled stone.

\subsection{Guidelines}

Two guidelines are relevant for recycling of waste: one for construction work and one for materials, such as plastics or chemicals. 


\subsubsection{Recycling within Construction Works}

For recycling of waste within construction work, e.g., roads or parking lots, the Swedish Environmental Protection Agency have published a guideline [1]. Although the guideline is not binding by law, it has become the ruling principle for these decisions. The ninth chapter of the guideline provides a level for when the environmental risk of recycling the waste is acceptable. For such cases, the waste material can be used without being subject to the permit or notification obligation according to Regulation 1998:899 on environmentally hazardous activities and health protection. The levels of low risk correspond to the 90th percentile of existing background level concentrations for substances to be phased out according to environmental targets. For substances that are not phasing-out substances, the level is based on a risk assessment where a $5 \%$ reduction of species can be noted.

These rules for recycling within construction works will be changed so that all treatment of waste becomes subject to permit or notification, or alternatively covered by general rules that ensure that the waste is treated in accordance with the Waste Directive (2008/98/EC). The Swedish Environmental Protection Agency has been commissioned to propose which activities may be suitable for general rules. The focus of the guideline will instead be, what it does not really deal with today, the assessment between using waste with notification or permit.

\subsubsection{Recycling of Materials}

The Swedish Environmental Protection Agency and the Swedish Chemicals Agency have together developed a guidance for safe material recycling [35]. The starting point for this guidance is that recycling can be done safely with regards to environmental and health impacts during the collection, processing and use of the recycled material. Based on material content, a scale is defined from cases with clean material streams when recycling should occur, to polluted material streams when recycling should not occur. According to the scale, only pure waste streams should be recycled. For more polluted material streams, the guidance argues that better knowledge and technology are required. Especially valuable materials can be recycled under strict control despite some dangerous content. Waste containing particularly hazardous substances should not be recycled. It is not clear during which circumstances 'better' technology or knowledge can be said to have been achieved.

From a risk management perspective, it is noted that the two guidelines above deal with risk through hazardous substance limit values in the material content. Recycling is controlled from a local environmental risk perspective. The two guidelines justify recycling decisions with a limit-based, i.e., deontological, approach.

\subsection{Recycling in Practice}

The picture that emerges from the interviews has the following main features: A local environmental risk assessment is by all parties considered to be the basis for the decisions. What differs is how strict the interpretation should be, what it should be based on and if a greater advantage in other areas, such as resource efficiency, can be weighed against an increased environmental risk. All parties also seem to agree that the same requirements should apply to virgin materials as well as recycled materials.

Since recycling of waste is often a complex problem that seem to require difficult balancing, there is a desire among businesses to be able to have a dialogue with governing authorities. However, the interviews convey that it is difficult to discuss with the authorities today due to the following factors.

- Resource shortage at governmental agencies.

- Communication mainly via e-mail, which results in that:

It is difficult to build a relationship,

$\bigcirc \quad$ It is difficult to build trust, and

It takes a long time. 
- Different departments and authorities are responsible for different parts.

In the Netherlands, the same authority is responsible for virgin and recycled materials. The same requirements are made regardless of the origin of the material. In Sweden, business ministries are responsible for virgin materials and environmental ministries are responsible for waste, which means that virgin materials become a business activity to be supported while waste-based resources become an environmental issue to control [36].

Based on the interviews, from an operational perspective, business economics (cost and time) is the driving and governing goal, which may conflict with environmental considerations.

\section{The Non-Toxic Environmental Target}

With sophisticated methods of analysis, it is now possible to detect very low concentrations of substances. One question that is raised during the interviews and the workshop is if there can be an acceptable level for dangerous substances or if materials need to be absolutely non-toxic. Another issue raised by the recycling businesses is whether it would be acceptable with dangerous substances if it is proven that there is no risk of harmful exposure to man and the environment? The Biotest method was mentioned at the workshop as a method that can be used to investigate whether a product or material is safe to use even though it may contain a certain content of a hazardous substance. DEHP was highlighted as an example. DEHP is classified as toxic, but when the substance is bound in a cable product, the substance is not bioavailable and thus an opinion was that DEHP should be allowed to be re-used in such products. Today there is no legislation or guideline that offers such a route in Sweden, although it seems to be possible based on the ECHA risk assessment process.

From a risk perspective it is realized that the risk of recycling decisions never is zero. There are various risks associated with a linear economy, mining, energy recovery and recycling. One view is therefore that a broader problem framing is needed where more types of risks and benefits are included. This includes both a local and a global perspective as well as present and future generations (long-term).

\section{Analysis}

The analysis aims to identify the link and discrepancy between theory and practice.

\subsection{Problem Framing}

How the recycling problem is framed affects how risks are managed. This section examines whether the problem has been appropriately framed based on the theory presented earlier.

Klinke and Renn [10] identify three challenges for risk management: complexity, uncertainty and ambiguity. Often all three challenges are apparent in recycling. Recycling is, by definition, complex when knowledge of the constituent substances is low in relation to cause and effect. An example is low concentrations of endocrine disruptors that can come from many different sources (what will be the weighted effect?). Uncertainty according to Klinke and Renn exists when a stronger prediction cannot be done due to knowledge limitations, such as the uncertainty regarding new substances. Ambiguity arises when authorities interpret goals in different ways, which occur in the recycling area. Deliberation processes are important for all three challenges above, but with different focus. According to Klinke and Renn, the important thing is to achieve both a process with the desired participation (legitimacy) and a good outcome (results). To deal with uncertainty, a broader analysis is required that includes stakeholders' concerns and socio-economic aspects. This is not captured in the more fact-based local environmental risk assessment. Citizenship dialogue with the aim of highlighting value conflicts and reaching broad agreements is the strategy that Klinke and Renn recommend for dealing with ambiguity.

The Swedish Environmental Protection Agency's guideline has been evaluated [2]. A guideline should be simple and practical to use so that it is applied consistently throughout Sweden. For simple and well-defined technical problems there is a possibility to write such guidelines (i.e., for 'hard' problems). 
Recycling is often defined as, and is in many ways, a 'hard' problem. How can waste A be recycled? Be cleaned? Replace virgin material B? However, it is sometimes difficult to move from hard facts and make decisions. Despite several years of research (generating hard facts), the question of whether waste A should be recycled often remains unsolved. Recycling is also an ambiguous and complex problem with conflicting goals, which opens for a 'soft' system perspective. Such a perspective can make the underlying worldviews and values visible. Recycling as a soft problem means that it is difficult to fully control each individual decision from a central point of view, especially by the use of specific guidelines. An important complement to this type of problem that falls outside the 'hard' guidelines is, based on theory, deliberation. At the same time, the interviews reveal that it is difficult for business practitioners to discuss with the authorities today. This is probably also linked to the bureaucratic new public management (NPM) governance that permeates most Swedish authorities today. Employees who are strictly controlled have little mandate for deliberations, especially when it comes to new ways of thinking or solving a problem. According to Fransson and Quist [37], re-professionalization takes time, but would create better conditions for dialogue with employees who felt safe to make decisions. A soft system perspective can include more aspects, which, from an ethical perspective, requires representatives from the three different parties: risk-expose, beneficiaries and decision-makers.

Decisions on recycling are made under uncertainties regarding the hazard and use of chemicals. At the same time, important values such as long-term sustainability are at stake. Funtowicz and Ravetz [9] argue that post-normal science ("post-normal science") is best suited for this type of decision (large uncertainties and values at stake). By post-normal science, they advocate a democratic form of problem-solving where everyone is legitimate to contribute to the problem's solution.

An example can be taken from waste incineration. Sweden has, as one of a few countries, managed to make waste incineration publicly acceptable. One contributing reason may be that the municipalities were obliged to develop municipal waste plans. This triggered local debate and decision-making on a municipality level. Thus, the decisions were anchored with local support. The citizen dialogue that was needed was then handled locally. There is no such dialogue for recycling of different waste and there is no requirement to make such plans locally.

\subsection{Specification of Objectives (and Risks)}

The choice of decision objective affects the risks that are made visible in the decision-making process. Risks are about all threats to the desirable outcomes that we value positively. According to Holmgren and Thedéen [12], the risk measure should be related to the decision situation in question. If we, as a society, have to choose between recycling or not, the consequences of both alternatives (to recycle and not to recycle) should be evaluated, with respect to all relevant goals, such as the Non-Toxic Environmental goal, the Resource Efficiency goal and the Climate goal.

\subsection{Alternatives and Possible Solutions}

Within decision theory (e.g., [5]), a status quo alternative for each individual decision must be defined as a sound frame of reference to evaluate other alternatives against. Normally, the status quo alternative initially consists of "do nothing"; however, for recycling it is not obvious which reference alternative this represents. Is it to use virgin material (i.e., not to recycle)? Or should a certain known and usual recycling process be the reference alternative? For a value neutral problem framing, it seems that it is better to evaluate the alternatives to recycle (in different ways) and not recycle to one another.

\subsection{Analysis and Evaluation}

Today, a local environmental risk assessment is the guiding method for ensuring that the Non-toxic target is met. This does not consider the environmental impact of, for example, mining of virgin materials or putting waste into landfills. Through a strict limit-based risk analysis principle on waste there are risks that even greater consequences of virgin material mining or landfill / energy recovery of waste are accepted instead. Even greater environmental risks may be taken than those we are trying to 
avoid. This is, according to the theory $[23,29]$ a consequence of limit-based risk management. If the limit is set too strict (we would off course like to have a non-toxic environment), it strikes back.

\subsection{A Broader Framing}

To take all relevant objectives and risks into account, a broader perspective is needed. In addition to local environmental risks, the global life cycle perspective can be added to analyse the objectives. However, a broader perspective may seem unnecessary for simpler cases. Possibly a compromise is to use a scale that goes from narrow to broad. For simpler cases, the narrower analysis may suffice, while there is an opportunity for broader analysis for recycling decisions that require a more nuanced trade-off between conflicting objectives, i.e., a combination of a limit-based and a utility-based approach:

1. Material composition, concentration limits (limit-based)

2. Limits for exposure and suitability (limit-based)
a. Use
b. Health Aspects
c. Leachability
d. Bioavailability/Biotest

3. Environmental benefits from a broader perspective (utility-based)

a. Cost-benefit analysis (risk of hiding ethical aspects)

b. Multi-criteria analysis (ethical aspects can naturally be included)

One can, however, question whether the above-mentioned scale with a large selection of analyses re-establish the historical dualistic path where virgin materials are free of analytical needs and recycled materials need to be handled. The stigma of waste as something negative to be controlled needs to be addressed. From a circular perspective, it should be the other way around: if you want to use virgin materials, you must show that it is not possible to obtain the corresponding recycled material. This is a deeply rooted paradigm to break and is linked to the fact that different authorities and regulations are responsible for virgin and recycled materials.

\subsection{Linked Decisions and a Long-Term Perspective}

Recycling decisions are largely what Hammond et al. [5] call linked decisions, which depend on previous decisions, e.g., the decisions that led to the creation of the waste, and future decisions, e.g., land use and future toxicological studies. In particular, two groups of linked decisions can be identified:

1. Decisions that lead to the use of virgin materials and hazardous substances in society's material cycles (linear economy).

2. Decisions that allow (circularity) or do not allow (linear) recycling within the material cycle.

Decisions that are made in Group 1 affect what decisions can be made in Group 2, and thus they are linked. Decision situation 1 is about hazardous substances being added to newly produced products. Tough regulation on hazardous substances in group 1 provides better conditions for circular flows in group 2. Strict regulation of hazardous substances in Group 2 results in reduced conditions for circular flows. One view from the interviews is that it is inconsistent to allow hazardous substances in situation 1, but not in situation 2. What is allowed to enter in decision 1 should, given a positive resource efficiency, also be allowed to recycle more times if it can be done with maintained safety. 


\subsection{Ethical Aspects}

There are many important parties involved in recycling problems. These stakeholders were discussed from an ethical perspective at the workshop meeting. The identified parties were:

- manufacturers and process industries that create products that sooner or later become waste and that can be more or less recyclable,

- waste collectors who receive or collect waste,

- businesses that can use (reuse or recycle) the waste,

- $\quad$ supervisory authorities, and

- $\quad$ risk-exposed people, animals and the environment.

People in general can, to the extent that they live in a functioning democracy and have influence over social decision-making, be seen as beneficiaries of the services and activities that sustain the welfare society. The most problematic risk-exposed group becomes animals and the environment since they do not benefit from industry and the welfare society.

According to REACH and CLP, the manufacturer is obliged to consider the entire life cycle of their product, but it is clear from the interviews that this does not mean that products today are recyclable. In many cases, the producer holds a favourable role as both beneficiary and decision maker. Here, there is a conflict between economy (producer's) and sustainability or environmental considerations (governmental and risk-exposed perspective). Stronger producer incentives seem to be necessary to make recyclable and non-toxic products.

From a deontological perspective, it is close at hand to see the right to a healthy environment as a duty: 'thou shalt not pollute'. If someone pollutes, the polluter should pay for it (according to the polluter pays principle). However, it can be argued that the duty of a non-toxic environment stands against other obligations, such as resource efficiency, or the right to an environment unaffected by climate change. It then becomes a matter of, in the event of conflict, putting the most important duty first. Although it can be argued that the duty on a non-toxic environment has a greater weight (the principle of proximity and active responsibility), it is not clear that the Non-Toxic Environmental target actually weighs most for the duty ethicist. Within deontological ethics, the idea is further that those obligations that are violated require compensation. However, it is doubtful how in practice we can compensate for dangerous substances in the environment, or the creation of irreversible processes such as climate change.

From a consequentialist perspective, no specific limit, duty or right is sought to guide the decision. Instead, the focus is on maximizing the utility, which includes all utilities. It does not matter if the effects occur locally or globally, all effects should be included. Consequently, the utilitarian advocates a broader perspective where more effects than local environmental risks are analysed. Thus, from a consequentialist perspective, the Non-Toxic Environmental target is weighed against other conflicting targets.

Figure 3 summarizes key factors from theory to practice and the lessons that can be learned. 


\begin{tabular}{|c|c|c|c|}
\hline \multirow{6}{*}{ 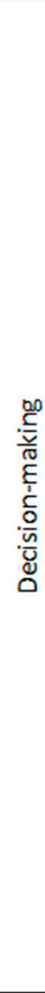 } & $\begin{array}{l}\text { Problem framing } \\
\text { (soft/hard problems, } \\
\text { complexity, } \\
\text { uncertainty and } \\
\text { ambiguity \& post- } \\
\text { normal science) }\end{array}$ & $\begin{array}{l}\text { To a large extent framed as a local } \\
\text { environmental 'hard' problem. } \\
\text { Controlled by local environmental risk } \\
\text { assessment and limit values. Limited } \\
\text { deliberation possibilities. }\end{array}$ & $\begin{array}{l}\text { A 'soft' problem view might be necessary } \\
\text { aiming at deliberation and a broader } \\
\text { problem framing, e.g. from the } \\
\text { perspective of the Swedish Environmental } \\
\text { Code. }\end{array}$ \\
\hline & $\begin{array}{l}\text { Specification of } \\
\text { objectives (and risks) }\end{array}$ & $\begin{array}{l}\text { Non-toxic environment is the governing } \\
\text { goal. }\end{array}$ & $\begin{array}{l}\text { According to theory, all relevant goals } \\
\text { that are affected by the decision should } \\
\text { be considered, e.g. also resource } \\
\text { efficiency and climate change. }\end{array}$ \\
\hline & $\begin{array}{l}\text { Alternatives and } \\
\text { possible solutions }\end{array}$ & $\begin{array}{l}\text { Authorities: de-toxify loops now. } \\
\text { Recycling businesses: this is ineffective } \\
\text { since toxic substances still enter the } \\
\text { loops. }\end{array}$ & $\begin{array}{l}\text { Consider recycling alternatives (in } \\
\text { different ways) against the "no recycling" } \\
\text { alternative. }\end{array}$ \\
\hline & Analysis (facts) & $\begin{array}{l}\text { The analysis is limited to local } \\
\text { environmental risk assessment. }\end{array}$ & $\begin{array}{l}\text { For tough decisions a broader analysis is } \\
\text { required that analyse the differences } \\
\text { between the alternatives with regards to } \\
\text { the specified objectives. }\end{array}$ \\
\hline & Evaluation (value) & $\begin{array}{l}\text { Limit values aiming at the Non-toxic } \\
\text { env. target. Trade-offs with other } \\
\text { environmental goals is not performed. }\end{array}$ & $\begin{array}{l}\text { Trade-off between all relevant objectives } \\
\text { to identify the alternative with the } \\
\text { greatest utility. }\end{array}$ \\
\hline & $\begin{array}{l}\text { Linked decisions and a } \\
\text { long-term perspective }\end{array}$ & $\begin{array}{l}\text { The non-toxic environment is the long- } \\
\text { term goal. Waste as something to be } \\
\text { controlled by the use of limits. }\end{array}$ & $\begin{array}{l}\text { Treat the use of material resources equal. } \\
\text { First new products that enter material } \\
\text { loops need to be "non-toxic", until then, } \\
\text { satisfy with safe recycling and products. }\end{array}$ \\
\hline \multirow{2}{*}{$\begin{array}{l}\text { U. } \\
\text { 点 } \\
\text { L }\end{array}$} & $\begin{array}{l}\text { Justification by a limit- } \\
\text { based and/or utility- } \\
\text { based approach }\end{array}$ & $\begin{array}{l}\text { A limit-based approach is taken in } \\
\text { existing national guidelines which leads } \\
\text { to limited recycling. Strict limits may } \\
\text { create even greater environmental risks. }\end{array}$ & $\begin{array}{l}\text { A limit-based approach is sometimes } \\
\text { insufficient. Justification by a utility-based } \\
\text { approach can strike trade-offs between } \\
\text { conflicting objectives. }\end{array}$ \\
\hline & $\begin{array}{l}\text { Ethical analysis of risk- } \\
\text { exposed, beneficiary } \\
\text { and decision-maker }\end{array}$ & $\begin{array}{l}\text { A local environmental perspective is } \\
\text { considered by tradition. The producer } \\
\text { holds a favourable role as both } \\
\text { beneficiary and decision-maker. }\end{array}$ & $\begin{array}{l}\text { Consider conscious beings that are risk- } \\
\text { exposed (globally). Stronger producer } \\
\text { incentives are necessary to ensure that } \\
\text { products are truly recyclable. }\end{array}$ \\
\hline
\end{tabular}

Figure 3. The factors identified in the theory section were used to analyse Swedish recycling in practice, which resulted in a set of lessons learned.

\section{Conclusions}

Risks should be managed based on a well-motivated choice of values, objectives, principles and methods. An explicit choice or an implicit "non-choice" will exclude alternative values, objectives, principles and methods. Sound decision making relies on all steps of the decision making process, from problem framing to evaluation.

Recycling decisions are often associated with complexity, uncertainty and ambiguity with large values at stake. Recycling can thus be framed as a characteristic 'soft' problem with conflicting objectives. An important complement to this type of problem that falls outside the 'hard' recycling problems is, based on theory, deliberation and democratic processes. This possibility needs to be strengthened in practice, see Figure 4. 
Recycling in Sweden today

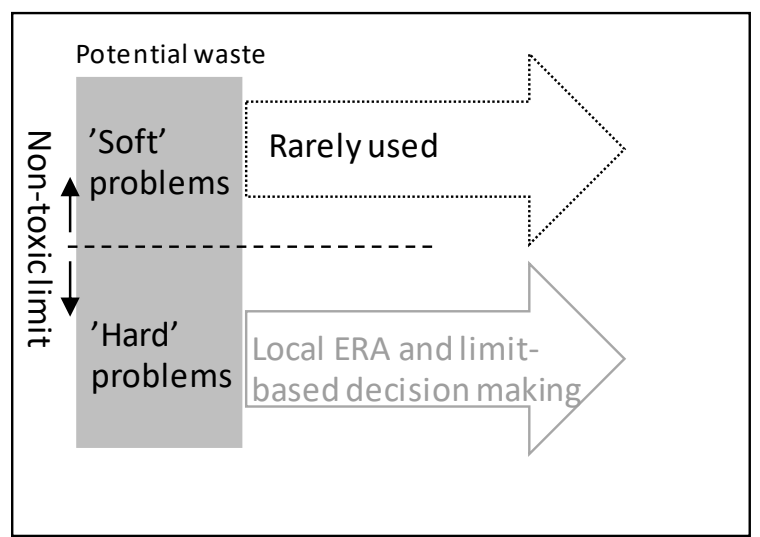

A way forward?

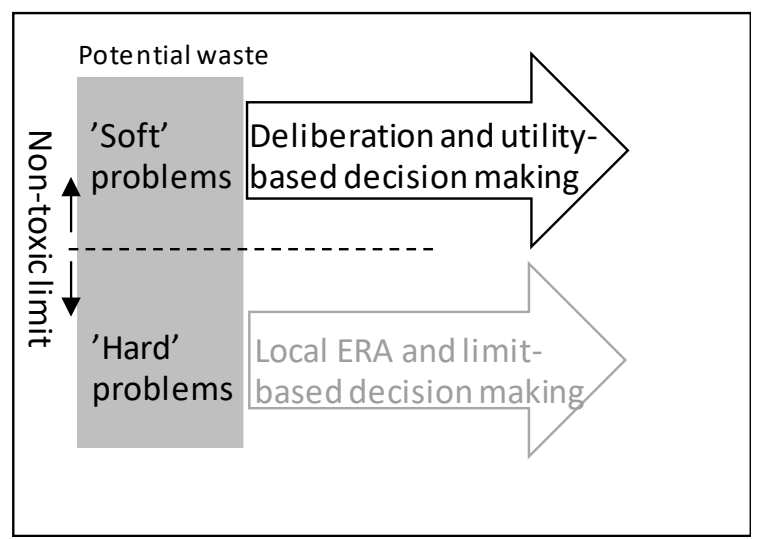

Figure 4. Recycling of what can be characterized as 'hard' problems can be solved using local environmental risk assessment and limit-based decision making. Recycling of what can be characterized as 'soft' problems are better solved via deliberation and utility-based decision making.

According to Hume's law, we cannot deduce, merely based on facts, how we should act. A valuation is necessary. There are primarily two normative ethical theories that can give us guidance; consequence ethics and deontological ethics. A deontological perspective manages risks with the help of limits and could give greater weight to the Non-Toxic Environmental target which is the strategy being used today in Sweden. However, it can be called into question if this target is more important than resource efficiency and the Climate target. Secondly it is questionable if the deontologist can compensate for other duties, such as climate change, that are violated. A consequentialist perspective advocates a utility-based approach where the Non-Toxic Environmental goal is weighed against other objectives, such as resource efficiency.

If recycling is seen as a decision problem, the choice is between to recycle (in different ways) or not to recycle (i.e., landfill, incineration or energy recovery). Based on decision theory, all the relevant goals should be considered. This requires a broader utility-based perspective for more difficult cases, which includes environmental risks linked to the different alternatives.

With a broader perspective, it is recognized that no alternative is risk-free. Deliberations and multi-criteria analysis can weigh the various factors against each other to see what alternative that offers the most utility, e.g., from the perspective of the Environmental Code. A broader perspective could increase recycling, favours long-term sustainability and, in the long run, all environmental goals.

However, a broader perspective would result in increased analysis for recycling decisions, with the result that the use of virgin material would still be favoured. All interviewed parties agree on that recycled and virgin material should be treated equally. Then, from a higher policy perspective, one should always have to show that environmental risks are minimized, and long-term sustainability promoted when material (recycled or virgin) is used (or that it is not possible to obtain corresponding recycled material).

Author Contributions: Conceptualization, J.G. and U.M.; methodology, J.G. and U.M.; formal analysis, J.G. and U.M.; investigation, J.G. and U.M. writing-original draft preparation, J.G.; writing-review and editing, J.G. and U.M.; All authors have read and agreed to the published version of the manuscript.

Funding: This research was funded by RE:Source which is a Swedish innovation program financed by Vinnova, Formas and Energimyndigheten.

Conflicts of Interest: The authors declare no conflict of interest.

\section{References}

1. Naturvårdsverket. Återvinning av Avfall i Anläggningsarbeten: Handbok 2010:1; Naturvårdsverket: Stockholm, Sweden, 2010. 
2. Naturvårdsverket. Utvärdering av Naturvårdsverkets Handbok för Återvinning av Avfall i Anläggningsarbeten; Naturvårdsverket: Stockholm, Sweden, 2015.

3. Hansson, S.O. Riskfilosofi, en Introduktion; Studentlitteratur: Lund, Sweden, 2011.

4. $\quad$ Ejvegård, R. Vetenskaplig Metod; Studentlitteratur: Lund, Sweden, 2003.

5. Hammond, J.S.; Keeney, R.L.; Raiffa, H. Smart Choices: A Practical Guide to Making Better Decisions; Harvard Business Review Press: New York, NY, USA, 2015.

6. Hansson, S.O. The Ethics of Risk: Ethical Analysis in an Uncertain World; Palgrave Macmillian: New York, NY, USA, 2013.

7. Lundgren, L. Kemikaliepolitike-ett Svårskött Pastorat. In Giftfri Miljö-Utopi eller Verklig Chans? Formas: Stockholm, Sweden, 2006.

8. Checkland, P. Systems Thinking, Systems Practice: Includes a 30-Year Retrospective; Wiley: Chichester, UK, 1999.

9. Funtowicz, S.; Ravetz, J. Three Types of Risk Assessment and the Emergence of Post-Normal Science. In Social Theories of Risk; Golding, K.A., Ed.; Praeger: Westport, Canada, 1992; pp. 251-273.

10. Klinke, A.; Renn, O.A. New Approach to Risk Evaluation and Management: Risk-Based, Precaution-Based, and Discourse-Based Strategies. Risk Anal. 2002, 22, 1071-1094. [CrossRef] [PubMed]

11. Weick, K.E. Ambiguity as Grasp: The Reworking of Sense. J. Conting. Crisis Manag. 2015, 23, 117-123. [CrossRef]

12. Holmgren, Å.; Thedéen, T. Riskanalys. In Risker i Tekniska System; Grimvall, G., Jacbosson, P., Thedéen, T., Eds.; Studentlitteratur: Lund, Sweden, 2003; pp. 253-274.

13. Hansson, S.O. Teknik och Etik; KTH Royal Institute of Technology: Stockholm, Sweden, 2009.

14. Hansson, S.O. Decision Theory: A Brief Introduction; KTH Royal Institute of Technology: Stockholm, Sweden, 1994.

15. Naturvårdsverket. Riskvärdering-Metodik och Erfarenheter; Naturvårdsverket: Stockholm, Sweden, 2006.

16. Mattsson, B. Riskhantering vid Skydd mot Olyckor. In Problemlösning och Beslutsfattande; Räddningsverket: Karlstad, Sweden, 2000.

17. Tingvall, C.; Haworth, N. Vision Zero-An Ethical Approach to Safety and Mobility. In Proceedings of the 6th ITE International Conference Road Safety \& Traffic Enforcement: Beyond 2000, Melbourne, Australia, 6-7 September 1999.

18. Tingvall, C. The Zero Vision: A Road Transport System Free from Serious Health Losses. Transp. Traffic Saf. Health 1997, 5, 37-57.

19. Belin, M.; Tillgren, P.; Vedung, E. Vision Zero-A road safety policy innovation. Int. J. Inj. Control Saf. Promot. 2012, 19, 171-179. [CrossRef] [PubMed]

20. Whitelegg, J.; Haq, G. Vision Zero: Adopting a Target of Zero for Road Traffic Fatalities and Serious Injuries; Stockholm Environment Institute: Norwich, UK, 2006.

21. Elvik, R. Can injury prevention efforts go too far?: Reflections on some possible implications of Vision Zero for road accident fatalities. Accid. Anal. Prev. 1999, 31, 265-286. [CrossRef]

22. Hermansson, H. Consistent risk management: Three models outlined. J. Risk Res. 2005, 8, 557-568. [CrossRef]

23. Ersdal, G.; Aven, T. Risk informed decision-making and its ethical basis. Reliab. Eng. Syst. Saf. 2008, 93, 197-205. [CrossRef]

24. Collste, G. Inledning till Etiken; Studentlitteratur: Lund, Sweden, 1996.

25. Kamm, F.M. Intricate Ethics: Rights, Responsibilities, and Permissible Harm; Oxford University Press: New York, NY, USA, 2007.

26. Brülde, B. The Human Good; University of Gothenburg: Gothenburg, Sweden, 1998.

27. Renn, O. The role of risk perception for risk management. Reliab. Eng. Syst. Saf. 1998, 59, 49-62. [CrossRef]

28. Söderqvist, T. Diskontering i Samhällsekonomiska Analyser av Klimatåtgärder; Naturvårdsverket: Stockholm, Sweden, 2006.

29. Basta, C. Siting risky facilities: Probabilism, determinism and beyond. Plan. Theory 2014, 13, 44-64. [CrossRef]

30. Peterson, M.; Jensen, K.K. Riskvärdering av Förorenad Mark-Etiska och Ekonomiska Perspektiv; Naturvårdsverket: Stockholm, Sweden, 2006.

31. Hansson, S.O. How to perform an ethical risk analysis (eRA). Risk Anal. 2018, 38, 1820-1829. [CrossRef] [PubMed]

32. Hermansson, H.; Hansson, S.O. A three-party model tool for ethical risk analysis. Risk Manag. 2007, 9, 129-144. [CrossRef]

33. Slovic, P. The risk game. J. Hazard. Mater. 2001, 86, 17-24. [CrossRef] 
34. Kemikalieinspektionen. Regler om Kemikalier i Kretsloppet för Varor-en Juridisk Analy; Kemikalieinspektionen: Stockholm, Sweden, 2014.

35. Naturvårdsverket. Giftfria och Resurseffektiva Kretslopp: Vägledning för Ökad och Säker Materialåtervinning; Naturvårdsverket: Stockholm, Sweden, 2017.

36. Johansson, N. How Can Conflict, Complexities and Uncertainties in a Circular Economy Be Handled?: A Cross European Study of the Institutional Conditions for Sweage Sludge and bottom Ash Utilization; KTH Royal Institute of Technology: Stockholm, Sweden, 2018.

37. Fransson, M.; Quist, J. Fri Som en Fågel: En Studie av Återprofessionalisering inom Försäkringskassan; Karlstad University: Karlstad, Sweden, 2018.

(C) 2020 by the authors. Licensee MDPI, Basel, Switzerland. This article is an open access article distributed under the terms and conditions of the Creative Commons Attribution (CC BY) license (http://creativecommons.org/licenses/by/4.0/). 